\title{
The influence of individual cognitive style on performance in management education
}

\author{
Steven J. Armstrong \\ Lincoln School of Management, \\ Department of Organisational Analysis \\ University of Lincolnshire and Humberside, \\ Brayford Pool, Lincoln, LN6 7TS. \\ United Kingdom
}




\title{
The influence of individual cognitive style on performance in management education
}

\begin{abstract}
This paper reports the outcomes of an empirical study undertaken to explore the possibility that cognitive style may be an important factor influencing performance on certain types of task in management education. Four hundred and twelve final-year undergraduate degree students studying management and business administration were tested using the Allinson-Hayes Cognitive Style Index. Their cognitive styles were then compared with assessment grades achieved for academic modules, the task categories of which were deemed to be consonant with either the wholist/intuitive or the analytic style of working. Overall ability defined by final degree grades was also tested against individuals' cognitive styles. As expected, students whose dominant cognitive styles were analytic attained higher grades for long term solitary tasks involving careful planning and analysis of information. However, contrary to expectations, performance on tasks believed to be more suited to the wholist/intuitive style was also higher for analytic individuals, as was overall ability defined by final degree grades. The results were discussed in terms of the nature of the tasks and the need for methods of performance assessment that are independent of an orientation bias. Without this, it is argued, employment selection criteria may favour the wrong type of candidate in some circumstances.
\end{abstract}


Whether or not cognitive style is related to ability is unclear. However, what is clear from the evidence available is that difficulties arise in interpreting the relationship because of the confounding influence of the tasks selected to measure ability. In order to determine whether or not a relationship exists, it is first of all important to try to determine the characteristics that distinguish style from ability because both will affect performance on a given task. Witkin et al (1977) differentiate between the two by emphasising the bi-polar nature of cognitive styles, unlike intelligence or other abilities. They suggest that each pole of cognitive style has adaptive value under specified circumstances whereas to have more of an attribute such as intelligence is better than to have less of it. This difference has been very well defined by Riding (1996):

\footnotetext{
'The basic distinction between them is that performance on all tasks will improve as ability increases, whereas the effect of style on performance for an individual will either be positive or negative depending on the nature of the task. It follows from this that for an individual at one end of the style dimension, a task of a type they find difficult will be found easier by someone at the other end of the dimension, and vice versa' (p2).
}

This leads to the interesting possibility that cognitive style may be an important factor influencing performance on certain types of task. The purpose of this study was to determine whether or not a relationship did exist between individuals' cognitive styles and their ability to perform well on tasks requiring different approaches to information gathering, processing and evaluation. The study also examined the relationship between cognitive style and overall ability. 


\section{Cognitive Style}

An individual's cognitive style may be defined as a self-consistent mode of functioning which individuals show in their perceptual and intellectual activities (Witkin et al, 1971).

Goldstein and Blackman (1978) suggest that this relates to the characteristic and habitual way in which an individual processes and evaluates information, solves problems and makes decisions. Riding et al (1993) suggested that cognitive style differences may be due to differences in left/right hemispheric specialisation of the brain which is a commonly held view shared by other researchers in the field (Mintzberg, 1976; Ornstein, 1977; Doktor, 1978; Robey \& Taggart, 1981; Agor, 1984; Taggert et al, 1985; Waber, 1989; Sonnier, 1990; Allinson \& Hayes, 1996). This connection between neuro-physiology and cognitive psychology stems from the pioneering work of Sperry (1964), Luria (1966), Gazzaniga (1967) and Bogen (1969). Their studies demonstrated the human left cerebral hemisphere to be specialised for primarily analytic, rational and sequential information processing and the right cerebral hemisphere to be specialised for primarily intuitive, holistic, and simultaneous information processing. Whilst some now regard this split brain formulation as an oversimplification (Rao et al, 1992), others (e.g. Languis, 1998; Languis \& Miller, 1992) continue to report patterns of brain mapping research which are consistent with Luria's (1980) theory of brain functioning. Irrespective of whether the left brain/right brain analogy is scientifically correct, it does nevertheless serve as a useful metaphor for describing these cognitive differences.

In a review of the literature, Armstrong (1999) identified 54 dimensions on which cognitive style has been differentiated. These include:

Field dependence-field independence (Witkin et al, 1962).

$>$ Reflective-impulsive (Kagan, 1965).

Serialist-holist (Pask \& Scott, 1972).

Converger-diverger (Hudson, 1968). 
Simultaneous-successive (Das, 1988).

Wholist-analytic (Riding, 1991).

Leveller-sharpener (Holzman \& Klein, 1954).

Although certain authors (e.g. Zelniker, 1989) argue that this multiplicity of constructs reflects the sheer complexity of cognition, others have suggested that they are merely different conceptions of a superordinate dimension (Messick, 1976; Kogan, 1983; Miller, 1987; Rayner \& Riding, 1997). On this basis, Riding and Douglas (1993) defined a principal cognitive style group comprised of the dimensions listed above. They labelled these the Wholist-Analytic cognitive style. These poles are also commonly labelled Intuitive-Analytic (Zeleny, 1975; Doktor, 1978; Agor, 1986; Hammond et al, 1987; Allinson \& Hayes, 1996)

In a work context, analytic individuals tend to be compliant, their thinking relies on logical sequences and vertical reasoning, they prefer structured approaches to decision making, apply systematic methods of investigation, and are especially comfortable when handling problems requiring a step by step solution. Wholist/intuitive individuals, on the other hand, would tend to be nonconformist, their thinking relies on impulsive synthesis and lateral reasoning, they prefer rapid, open-ended approaches to decision making, they rely on random methods of exploration and work best on problems favouring a holistic approach (Allinson, Armstrong \& Hayes, forthcoming; Zeleny, 1975; Lynch, 1986).

\section{Relationship Between Cognitive Style and Ability}

In answer to the question of whether cognitive style is related to ability, several notable researchers have agreed that cognitive styles are different from intellectual abilities in multiple and important ways (Witkin et al, 1977b; Sharma, 1986; Keefe, 1988). Campbell (1991) shares similar views to Messick (1984) who believes that intellectual ability refers to 
what kind of information is being processed by what operation, in what form and how well, whereas cognitive styles refer to the manner or mode of cognition - to the question of how.

However, as Miller (1987) observed, the relationship between style and ability continues to be a thorny problem in the cognitive style literature, one that is exemplified by the controversy over field dependence/independence (Witkin et al, 1971) and in particular the Group Embedded Figures Test (GEFT). A number of empirical studies using this test have suggested that cognitive style may be related to ability in some way. For example, it has been shown that field-independent children learn new computer languages more quickly and make less errors than their field-dependent counterparts (Watson \& Brinkley, 1992; Easton \& Watson, 1993; Cavaiani, 1989). Similar findings have been reported for abilities in the learning of language, (Jamieson, 1992), biological sciences (MacNab et al, 1991), mathematics (Van-Blerkom, 1988), mechanical drafting (Guster, 1986), and performance in multiple choice tests used to measure ability in a wide variety of subjects (Armstrong, 1993). Renninger and Snyder (1983) also found that field independent secondary students scored higher on standardised measures of academic ability. Some researchers have criticised the Field Dependence/Independence dimension for not actually measuring cognitive style (Guilford, 1970; Kagan, 1976) and it has been suggested that it may measure some component of cognitive ability instead (Kush, 1996; Sweiger, 1983; Goldstein \& Blackman, 1978, p185; Flexer \& Roberge, 1980). MacLeod et al (1986) attributed this to the degree of overlap between this dimension and the construct of spatial ability, which plays a key role in theories of intelligence. Riding and Pearson (1994) found some support for this in their investigations using the British Abilities Scale Short Form (Elliot, 1983) to measure intelligence. Whilst they found no significant relationship between cognitive style and intelligence using the Cognitive Styles Analysis instrument (Riding, 1991) they did find a relationship between intelligence and a Test of Embedded Shapes (Pearson, 1991) which is similar to GEFT. 
But other measures have also revealed significant relationships between cognitive style and ability. Researchers using Kolb's (1976) Learning Styles Inventory, for example, have found that style influences academic performance in computer engineering (Sein \& Robey, 1991), statistics (Hudak and Anderson, 1990), optometry (Sparks, 1990), business studies (Geiger, 1991) and numerical aptitude (Green and Parker, 1989). Furthermore, Letteri (1980) demonstrated how a cognitive profile could be mapped, using seven separate bi-polar dimensions, to significantly differentiate between high and low academic performers. High performers were characterised, according to the seven cognitive style dimensions, as being analytical (field independent), focuser, narrow, complex, reflective, sharpener and tolerant. Low academic performers were characterised as being global (field dependent), nonfocuser, broad, simple, impulsive, leveller, intolerant. Similar studies (e.g. Frederico \& Landis, 1984) using multiple instruments to measure cognitive styles have also shown styles to be related to abilities and aptitudes. Whilst some researchers might agree with previous views (e.g. Vernon, 1972; Wardell \& Royce, 1978) that measures of cognitive style therefore do not define a dimension distinct from general intelligence, it is important to consider that these studies do not adequately discuss the nature of the tasks used to measure ability. Because these may have favoured one cognitive style (e.g. analytic) over the other (e.g. wholist/intuitive), the question of whether these results support a link between styles and ability must again remain unanswered. Some authors (e.g. Globerson et al, 1985) have even suggested that controversies over the use of Field Dependence/ Independence instruments may be due to inappropriate selection of tests to measure ability,

'our findings seem to support the notion that the correlations between IQ and field dependence/independence reported in the literature may be due to incompatibility between the demands of a few sub-tests of the intelligence scale and the habitual information-processing strategies of the field dependent subjects' ( p690). 
In the context of the present study, the preceding discussions therefore highlight the importance of paying careful attention to the following points in order to minimise the effect of potentially confounding variables:

- Instruments for measuring cognitive style that are indexed by success in isolating a particular geometric pattern inside a larger pattern should be avoided due to a potential overlap with spatial ability and probably intelligence.

- The types of task used to evaluate subjects' ability/performance need to be considered carefully because these may favour one cognitive style over the other.

\section{Research Hypotheses}

There appears to be some evidence pointing to the possibility that instruments such as Witkin’s GEFT (Streufert \& Nogami, 1989; Widiger et al, 1980) and Kagan's MFFT (Streufert \& Nogami, 1989) may measure some aspect of intelligence as well as cognitive style. However, we have seen that this distinction is often blurred and the overall balance of evidence suggests that the cognitive style construct, itself, and overall ability or intelligence are unrelated (Riding \& Pearson, 1994). In the present study involving a sample of students in their final year of a Business Administration Degree, it is therefore hypothesised that (Hypothesis 1) there will be no significant difference in overall degree grades for students who fall into either the wholist/intuitive category of cognitive style or the analytic category.

One interesting possibility, however, is that cognitive style may be an important factor influencing performance on certain types of task. For example:

(a) In a task requiring an individual to see a problem in its overall context in order to arrive at a balanced view from which he/she would make important decisions, wholist/intuitive types are likely to excel over analytics because the latter will be 
more inclined to focus on one aspect of the overall situation to the exclusion of others. Similarly, in a situation where it is important to generate ideas rapidly, or where working with others is an important component in a decision making process, wholist/intuitive types are again likely to excel.

(b) Conversely, where tasks require careful planning and analyses of information to solve detailed problems, or where logical, reflective and linear approaches are required for long term solitary tasks, analytical types are likely to excel over wholist/intuitives because of the difficulty they experience in separating-out a situation into its constituent parts.

This leads to the main research hypotheses that assessment grades achieved for academic modules deemed to be consonant with one, or other of the above categories will be dependent on individuals' cognitive styles. For example, one module requires the students to undertake a project the published criteria of which state that it must be an individual piece of research which is problem solving in nature, requiring detailed and systematic collection and analysis of secondary and primary data. The students must demonstrate synthesis and evaluation of solutions, and a logical and linear progression through careful planning and scheduling. This task, which culminates in the submission of an 8000-word dissertation after a project duration of eight months, is deemed to be consonant with the scenario defined under category (b) above. This leads to the hypothesis that (Hypothesis 2) the more analytic a student's cognitive style, the higher will be his or her research project grade.

Another module requires these students to undertake a unit of study in Business Policy and Strategy, the published learning aims of which require the students to synthesise issues relating to the global environment in order to understand the organisation as it moves through time, and in order to define appropriate strategies. It is also a requirement that functional aspects, studied separately in other units, are drawn together to evaluate how they should contribute to the overall purposes and aims of an organisation as a whole. Finally, it is also 
expected that knowledge of theoretical models will be supplemented by case study evaluation in student work-groups. Mintzberg (1989) reported that success in policy and strategy level processes such as these depend on management thinking that is more relational, holistic and intuitive than ordered, sequential and analytical. This sort of work is deemed to be consonant with the scenario defined under category (a) above. It is therefore hypothesised that (Hypothesis 3) the more intuitive a student's cognitive style, the higher will be his or her Business Policy and Strategy unit grade.

Finally, another unit of study requires students to develop an understanding of individual stages and inputs to marketing planning by developing skills in analysing practical marketing problems and formulating appropriate marketing strategies to deal with them. The unit encourages and facilitates the application of the theories, concepts and techniques of marketing management, and publishes learning outcomes from which the students must demonstrate management of the overall planning, implementation and control processes of marketing. Students are expected to apply techniques and models to the marketing planning process, to undertake comprehensive analysis of markets, customers and competitors, to develop a marketing plan, and to communicate analyses effectively using both written and verbal formats. Mintzberg (1989) reported that planners of this kind are expected to proceed in their work through a series of logical, ordered steps, each one involving explicit analysis. This work is therefore deemed to be consonant with the scenario defined under category (b) above. Hence, it is hypothesised that (Hypothesis 4) the more analytic a student's cognitive style, the higher will be his or her Marketing Planning unit grade.

\section{METHOD}

\section{Sample}

The sampling frame was comprised of 731 students studying for their final year of a B.A. degree in Business Administration at a University in the North of England between 1995 and 
1998. Four hundred and twelve students returned questionnaires, which represents an overall response rate of 56 per-cent. Two hundred and three of the student responses were from women, representing 49 per-cent of the overall sample.

\section{Measures}

Cognitive Style

The Cognitive Style Index (CSI) (Allinson \& Hayes, 1996), a self-report questionnaire designed to assess the superordinate dimension of cognitive style described above was administered to all students in order to assess the generic, intuitive-analytic dimension of cognitive style. Each of the 38 items has a true-uncertain-false response mode, and scores of 2, 1 or 0 are assigned to each response, the direction of scoring depending upon the polarity of the item. The nearer the total score to the theoretical minimum of zero, the more intuitive the respondent and the nearer to the theoretical maximum of 76 , the more analytical the respondent. Reliability of the CSI is good with test-retest correlations ranging from 0.78 to 0.90 (Allinson \& Hayes, 1996; Armstrong, 1999; Murphy et al, 1998) for subjects re-tested after intervals of up to 8 weeks, and Cronbach alpha coefficients ranging from 0.86 to 0.92 (Armstrong, 1999; Allinson \& Hayes, 1996; Murphy et al, 1998) for various managerial, professional and student groups. Construct validity is indicated by items loading on to a single factor in most previous studies, and significant correlations with, for example, scores on the Myers-Briggs Type Indicator (Myers, 1962), various personality dimensions and job level (Allinson \& Hayes, 1996).

\section{Ability}

Overall academic achievement was determined by collecting data from the University records system for final, overall degree grades of individual students. A 16-point scale where zero indicates catastrophic failure and sixteen indicates maximum possible academic achievement 
is used to represents this. This was deemed to be an accurate representation of a student's overall ability due to the fact that this final grade represents an aggregation of scores from a wide range and variety of business studies subjects.

Ability on tasks believed to be consonant with the scenarios suited to particular cognitive styles discussed above was determined by extracting grade points from the University records system for the Business Policy and Strategy Unit, Marketing Planning Unit, and Research Dissertation Unit. These grades were represented on the same 16-point scale described above.

\begin{abstract}
ANALYSIS AND RESULTS
Table I shows statistical analyses using independent samples t-tests that revealed there were no significant differences between grades achieved by males and females for any of the units studied. Subsequent analyses into the effects of cognitive style on performance were therefore considered to be gender neutral. However, it was revealed that female management students were more analytic $(\mathrm{M}=44.32, \mathrm{SD}=11.72, \mathrm{n}=203)$ than male management students $(\mathrm{M}=41.23, \mathrm{SD}=11.66, \mathrm{n}=218)$. The difference was significant $(\mathrm{t}=2.71, \mathrm{p}<$ $.01)$.
\end{abstract}

Table I about here.

In order to test the effects of cognitive style on performance, the student sample was divided into two groups on the basis of their cognitive styles. CSI scores were designated low (intuitive) or high (analytic) according to whether they were $\leq$ or $>43$. These thresholds were chosen to ensure two groups of approximately equal size. Table II shows descriptive statistics and the results of a series of independent samples t-tests for the two groups of intuitive and analytic individuals. 


\section{Table II about here.}

A potential problem with dichotomising data in the manner described is that if one student has a cognitive style index of 43 , and another has an index of 44 , they are considered to be different (i.e. intuitive and analytic respectively). The sample of students was therefore divided into three groups on the basis of their cognitive styles in order to extend the data analyses. CSI scores were designated low (intuitive), medium (integrated) or high (analytic) according to whether they were $\leq 38$, between $39 \& 48$, or $\geq 49$. These thresholds correspond to the $33^{\text {rd }}$ and $66^{\text {th }}$ percentile scores of the sample. Table III shows descriptive statistics and the results of a series of one-way analyses of variance tests for the three groups of individuals. Support for this approach can be found in the work of Agor (1984), who discusses three broad types of management style for making decisions. He talks of the left brain types stressing the employment of analytical and quantitative techniques. In the complementary style using right brain skills, he suggests that reliance is placed on feelings before facts when making decisions, where problems are solved by looking at the whole often with inadequate information or data at hand. A third style, he suggests, would be called integrated, employing both left and right brain skills interchangeably as the situation demands.

\section{Table III about here.}

These results will now be considered in four sections as defined by research hypotheses 1,2 , $3, \& 4$.

\section{Cognitive Style and Overall Degree Performance (Hypothesis 1)}

An independent samples " $t$ " test revealed that analytic students from the academic sample achieved higher overall degree grades $(M=10.20, S D=1.66, n=190)$ than intuitive students $(M=9.77, S D=1.65, n=176) . \quad$ The difference was significant $(t=-2.47, p=.014) . \quad A$ 
correlational analysis for the whole academic sample also revealed a statistically significant, though weak relationship between students' cognitive styles and degree grade $(\mathrm{r}=+.110, \mathrm{n}=$ $336, \mathrm{p}<.05$, two tails).

The analyses of variance reported in Table III also show that analytic students achieve significantly higher overall degree grades than do intuitive students. Students falling into the integrative category, however, achieve grades between these two groupings though the differences are not significant.

Hypothesis 1 is therefore rejected.

Cognitive Style and Performance in the Business Policy and Strategy Unit (Hypothesis 2)

An independent samples " $\mathrm{t}$ " test on the academic sample revealed that there was no significant difference $(\mathrm{t}=-1.12, \mathrm{p}>.05)$ between grades awarded for analytic students $(\mathrm{M}=$ 9.59, $\mathrm{SD}=2.19, \mathrm{n}=190)$ and intuitive students $(\mathrm{M}=9.33, \mathrm{SD}=2.17, \mathrm{n}=174)$ studying the Business Policy and Strategy unit.

However, the analyses of variance reported in Table III show that analytic students achieve significantly higher grades for this unit than do students falling into either the intuitive or the integrative groupings which directly opposes the research hypothesis.

Hypothesis 2 is therefore rejected.

Cognitive Style and Performance in the Marketing Planning Unit (Hypothesis 3)

An independent samples " $t$ " test revealed that analytic students from the academic sample achieved higher grades $(M=10.28, S D=1.92, n=106)$ than intuitive students $(M=9.56, S D$ $=2.07, \mathrm{n}=88)$ studying the Marketing Planning unit. The difference was significant $(\mathrm{t}=$ 
$-2.52, \mathrm{p}<.01)$. A correlation analysis revealed a statistically significant relationship between students' cognitive styles and grades awarded $(\mathrm{r}=+.205, \mathrm{p}<.01$, two tails, $\mathrm{n}=194)$.

As was the case with overall degree grades, the analyses of variance reported in Table III also show that analytic students achieve significantly higher overall degree grades than do intuitive students. Once again, students falling into the integrative category achieve grades between these two groupings but the differences are not significant.

Hypothesis 3 is therefore accepted.

Cognitive Style and Performance in the Research Dissertation Unit (Hypothesis 4)

An independent samples " $t$ " test revealed that analytic students from the academic sample achieved higher grades for their final year research projects $(M=10.30, S D=3.07, n=209)$ than intuitive students $(\mathrm{M}=9.70, \mathrm{SD}=2.89, \mathrm{n}=192)$. The difference was again significant $(\mathrm{t}=-2.05, \mathrm{p}<.05)$.

However, the analyses of variance reported in Table III reveal no significant differences between the analytic, integrative or intuitive student groupings. Support for Hypothesis 4 is therefore mixed.

\section{DISCUSSION AND CONCLUSIONS}

The primary purpose of the present study was to determine whether cognitive style was an important factor influencing performance on tasks the categories of which were deemed to be consonant with individuals' styles of working. In two of the three criteria examined, statistically significant results were obtained that linked cognitive style to performance. As hypothesised, individuals whose dominant cognitive styles were analytic performed significantly better than those whose cognitive styles were wholist/intuitive when performing 
tasks requiring detailed and comprehensive data collection, evaluation and analysis in order to carefully develop a marketing plan. Once again, as hypothesised, students who engaged in the solitary task of producing an 8000-word research dissertation requiring detailed and systematic collection and analysis of data, and who were expected to demonstrate logical and linear progression through careful planning and scheduling over an eight month period, performed significantly better when their dominant cognitive styles were analytic.

However, there was no support for the hypothesis that wholist/intuitive individuals would perform better on tasks relating to business policy and strategy formulation, believed by some (e.g. Mintzberg, 1989) to be better suited to individuals sharing this dominant mode of cognitive style. Indeed, it was rather surprising to find that when the sample was tri-chotomised into intuitive, integrative and analytic cognitive style groupings, analytic individuals also performed better than the other two groups in this unit of study.

A secondary aim of the study was to test the hypothesis that cognitive style is unrelated to overall ability for students of Business and Management Studies. Again, a rather surprising result revealed that individuals whose dominant cognitive styles were analytic significantly out-performed those whose cognitive styles were wholist/intuitive.

From earlier discussions in this paper, it is clear that cognitive style, in itself, is unlikely to be related to intelligence. Kirton (1978) and Riding \& Pearson (1994) presented empirical evidence of this when they reported an orthogonal relationship between cognitive style and intellectual ability. Direct relationships which have been reported in the literature are likely to be due either to the use of cognitive style instruments which overlap style with spatial ability and therefore intelligence, or to inappropriate methods of assessing intelligence/ability which may favour one cognitive style over the other. With respect to the former, a cognitive style instrument was chosen for the present research that did not depend on spatial ability. With respect to the problem of using inappropriate measures of ability, this study has 
attempted to overcome this by deliberately choosing performance indicators which stem from subject areas believed to be consonant with (e.g. policy \& strategy, planning, research) or in dissonance with (e.g. overall degree grades) particular cognitive styles. So why should students with analytic cognitive styles perform significantly better in the Policy and Strategy Unit and on overall ability defined by final degree grades? One variable that was not properly controlled was the method of assessment applied to these various units of study. This would have been difficult due to the fact that assessment methods were rigidly defined in course documentation, validated through formal university policies and procedures. The question of whether these assessment methods had an effect on the reported results, however, requires further consideration.

If one considers that the overall results appear to have demonstrated that analytic individuals are favoured over intuitive individuals in terms of their ability to achieve higher performance grades in the field of Business and Management Studies, it may be argued that this leads to a potentially serious dilemma. This dilemma arises from the fact that organisations have a strong tendency in their graduate recruitment process to favour those with higher degree classifications. According to the findings of this study, this also reflects the degree to which these individuals are analytic rather than intuitive. But some authors (e.g. Mintzberg, 1989; Taggart et al, 1985; Simon, 1987) have argued that intuition is favoured over analysis where key managerial processes are involved. For example, Mintzberg $(1989, \mathrm{p} 49)$ reports that:

'The key managerial processes are enormously complex and mysterious (to me as a researcher, as well as to the managers who carry them out), drawing on the vaguest of information and using the least articulated of mental processes. These processes seem to be more relational and holistic than ordered and sequential, more intuitive 
than intellectual; they seem, in other words, to be most characteristic of right-brain activity'.

This raises the important question of whether or not academic institutions are assessing the appropriate skills. If potential employers of Business and Management students are seeking to recruit graduates who possess, metaphorically speaking, these right brain skills, then existing methods of assessing the ability of Business and Management students might reasonably be questioned. Referring to the methods of assessment and marking criteria for the units of study considered in the present research (Table IV), it can be seen that there is a strong likelihood of there being an orientation bias favouring individuals whose dominant cognitive styles are analytic. These assessment methods, typical of many Business Schools, are predominantly reliant on written assignment formats where assessment criteria are based on the expectation of systematic analysis and evaluation of information resulting in cogent, structured, and logically-flowing arguments. Although analytic students, who tend to prefer structured situations that are impersonal in nature, may prefer such methods, they are unlikely to be suited to intuitive students who tend to have a predominantly social orientation, favouring interpersonal situations that allow interaction (e.g. Armstrong, 1999a; Armstrong, 1999b; Allinson, Armstrong, \& Hayes, (under review). Many alternative and innovative forms of assessment are available which would appeal to this type of student, such as poster sessions, video production, debating, role play, group-work with oral presentations, and so on. If assessment methods cannot be devised which are totally independent of orientation bias, perhaps they can at least ensure that equal amounts of analysis and intuition are assessed during the learning process (a whole brain approach).

\section{Table IV about here.}


Whilst selecting instructional techniques most appropriate to the cognitive styles of learners has often been considered to be a positive step in optimising learning processes, matching the type of assessment with the cognitive needs of students has seldom been attempted. This is an important area for future research because if the actual assessment of ability is biased in favour of those able to use their analytical skills more effectively, then employment selection criteria based, for example, on degree classifications may favour the wrong type of candidate in some circumstances.

\section{REFERENCES}

Agor, W. H. (1984). Intuitive Management. Englewood Cliffs, N.J: Prentice Hall.

Agor, W. H. (1986). The logic of intuitive decision making: A research-based approach for top management. New York: Quorum Books.

Allinson, C. W., Armstrong, S. J. \& Hayes, J. (under review). The effects of cognitive style on leader-member exchange: a study of manager-subordinate dyads.

Allinson, C. W. \& Hayes, J. (1996). The Cognitive Style Index: A Measure of Intuition-Analysis for Organisational Research. Journal of Management Studies, 33, $1,119-135$.

Armstrong, A.M. (1993). Cognitive style differences in testing situations. Educational Measurement: Issues and Practice, 12, 3, 17-22.

Armstrong, S. J. (1999a). Cognitive style and dyadic interaction: a study of supervisors and subordinates engaged in working relationships. Unpublished $\mathrm{PhD}$ thesis, University of Leeds, UK.

Armstrong, S. J. (1999b). Individual Differences in Cognitive Style and their Potential Effects on Organisational Behaviour: a summary of recent empirical studies. In R. Riding 
and S. Rayner (Eds.), International Perspectives on Individual Differences, London: Ablex Publishing.

Armstrong, S. J., Allinson, C. W. \& Hayes, J. (1999). Formal mentoring systems: an examination of the effects of mentor/protégé cognitive styles on the mentoring process. Change and Development Journeys into a Pluralistic World, Academy of Management Meeting, Chicago, USA (Aug.)

Armstrong, S. J. \& Priola, V. (under review). Individual cognitive styles and the composition of self-managing work-teams: an empirical study.

Bogen, J. E. (1969). The other side of the brain II: An appositional mind. Bulletin of the Los Angeles Neurological Societies, 34, 3, 313-320.

Campbell, B. J. (1991). Planning for a Student Learning Style, Journal of Education for Business, Jul, 356.

Cavaiani, T.P., (1989) Cognitive Style and Diagnostic Skills of Student programmers. Journal of Research on Computing in Education, 21, 4, 411-420.

Das, J. P. (1988). Implications for School Learning. In Schmeck, R. R. (Ed.), Learning Strategies and Learning Styles, New York, Plenum Press.

Doktor, R. (1978). Problem solving styles of executives and management scientists. TIMS studies in the management sciences, 8, 123-134.

Easton, C.E., \& Watson,J.A. (1993) Spatial Strategy Use During Logo Mastery: The Impact of Cognitive Style and Development Level. Journal of Computing in Childhood Education, 4, 1, 77-96.

Elliot, C. (1983). The British Ability Scales. Windsor, NFER.

Flexer, B. K. \& Roberge, J. J. (1980). IQ, field dependence-independence, and the development of formal operational thought. Journal of General Psychology, 103, 191-201.

Frederico, P.A. \& Landis, D.B. (1984)Cognitive styles, abilities, and aptitudes: are they dependent or independent? Contemporary Educational Psychology, 9, 146-161. 
Gazzaniga, M. S. (1971). Changing hemisphere dominance by changing reward probability in split-brain monkeys. Experimental Neurology, 33, 412-419.

Geiger, M. A. (1991). Performance during the first year of college: differences associated with learning style. Psychological Reports, 68, 633-634.

Globerson, T., Weinstein, E., \& Sharabany, R. (1985). Teasing out cognitive development from cognitive style; a training study. Developmental Psychology, 21, 4, 682-691.

Goldstein, K. M. \& Blackman, S. (1978). Cognitive Style: Five approaches and relevant research. New York, Wiley Interscience.

Green, D., \& Parker, R.M., (1989) Vocational and Academic Attributes of Students with Different Learning Styles. Journal of College Student Development, 30, 5, 395-400.

Guilford, J. (1970). The nature of Human Intelligence. New York: McGraw-Hill.

Guster, D., (1986) Cognitive Style and Drafting Performance. Journal of Vocational Education Research, 11, 1, 25-40.

Hammond, K. R., Hamm, R. M., Grassia, J. \& Pearson, T. (1987). Direct comparison of the efficacy of intuitive and analytical cognition in expert judgement. IEEE Transactions on systems, man and cybernetics, 17, 5, 753-770.

Holzman, P. S. \& Klein, G. S. (1954). Cognitive system-principles of levelling and sharpening: individual differences in visual time-error assimilation effects. Journal of Psychology, 37, 105-122.

Hudak, M.A., \& Anderson, D.E., (1990) Formal Operations and Learning style Predict Success in Statistics and Computer Science Courses. Teaching of Psychology, 17, 4, 231-234.

Hudson, L. (1968). Frames of mind: Ability perception and self-perception in the arts and sciences. London: Methuen. 
Jamieson, J. (1992). The cognitive styles of reflection/impulsivity and Field dependence/independence and ESL success. The Modern Language Journal, 76, 491-501.

Kagan, J. (1965). Individual Differences in the Resolution of Response Uncertainty, Journal of Personality and Social Psychology, 2, 2, 154-160.

Keefe, J. W. (1988). Learning Style Profile Handbook: Vol II, accommodating perceptual study and instructional preferences (Reston, VA, NASSP)

Kirton, M.J. (1978). Have adaptors and innovators equal levels of creativity?. Psychological Reports, 42, 695-698.

Kolb, D. A. (1976). The Learning Style Inventory: Technical Manual. Boston, MA;McBer.

Kush, J.C., (1996) Field dependence, cognitive ability, and academic achievement in Anglo American and Mexican American students. Journal of Cross-Cultural Psychology, 27, 5, 561-575.

Languis, M.L., (1998). Using knowledge of the brain in educational practice. NASSP Bulletin, 82, pp 38-47.

Languis, M.L. \& Miller, D.C. (1992). Luria's Brain Functioning Theory: A Model for Research in Cognitive Psychophysiology. Educational Psychology,27, pp 493-511.

Letteri, C. A. (1980). Cognitive Profile: Basic determinant of academic achievement, Journal of Educational Research,73, 195-199.

Lynch, D. (1986). Is the brain stuff still the right (or left) stuff?. Training and Development Journal, February, 23-26.

Luria, A. R. (1966). Higher Cortical Functions in Man, New York: Basic Books.

Luria, A.R. (1980). Higher Cortical Functions in Man, $2^{\text {nd }}$ ed. New York: Wiley.

MacLeod, C.M., Jackson, R.A., \& Palmer, J. (1986) On the relation between Spatial Ability and Field Dependence. Intelligence, 10, 141-151. 
Macnab, W., Hansell, M.H., \& Johnstone, A.H. (1991) Cognitive style and analytical ability and their relationship to competence in the biological sciences. Journal of Biological Education, 25, 2, 135-139.

Messick, S. (1976). Personality consistencies in cognition and creativity. In Messick,S. and Associates (Eds), Individuality in Learning. San Francisco, CA: Jossey Bass, 4-22.

Messick,S. (1984). The nature of cognitive styles: problems and promise in educational practice, Educational Psychologist, 19, 2, 59-74.

Miller, A. (1987). Cognitive Styles: an integrated model. Educational Psychology, 7, 4.

Mintzberg, H. (1976). Planning on the left side and managing on the right. Harvard Business Review, Jul, 49-58.

Mintzberg, H. (1989). Mintzberg on Management. Macmillan Free Press: New York.

Murphy, H. J., Kelleher, W. E., Doucette, P. A., \& Young, J. D. (1998). Test-Retest Reliability and Construct Validity of the Cognitive Style Index for Business Undergraduates. Psychological Reports, 82, 595 - 600.

Myers, I. B. (1962). Manual: The Myers Briggs Type Indicator. Palo Alto: Consulting

Ornstein, R. E. (1977). The Psychology of Consciousness, $\left(2^{\text {nd }}\right.$ Ed). New York: Harcourt, Brace, Jovanovich.

Pask, G., \& Scott, B.C. (1972). Learning strategies and individual competence. International Journal of Man-Machine Studies, 4, 217-253.

Pearson, F. (1991). Cognitive style related to the design process. International Journal of Technology and Design Education, 1, 152-158.

Rayner, S., \& Riding, R. (1997). Towards a Categorisation of Cognitive Styles and Learning Styles. Educational Psychology, 17, 5 - 27. 
Rao, H. R., Jacob, V. S., Lin, F., Robey, D. \& Huber, G. P. (1992). Hemispheric specialisation, cognitive differences, and their implications for the design of decision support systems. MIS Quarterly, 16, 145-151.

Renninger, K. A. \& Snyder, S. S. (1983). Effects of Cognitive Style on perceived satisfaction and performance among students and teachers. Journal of Educational Psychology, 75, 5, 668-676.

Riding, R. (1991). Cognitive Styles Analysis User Manual. Birmingham: Learning and Training Technology.

Riding, R. \& Pearson, F. (1994). The Relationship between Cognitive Style and Intelligence. Educational Psychology, 14, 4.

Riding, R. (1996). On the Nature of Cognitive Style. Discussion paper for Learning Styles Workshop, University of Birmingham (April).

Riding, R., Glass,A. \& Douglas, G. (1993). Individual Differences in Thinking: cognitive and neurophysiological perspectives, Educational Psychology, 13, 3 \& 4.

Riding, R. \& Douglas, G. (1993). The effect of cognitive style and mode of presentation on learning performance. British Journal of Educational Psychology, 63, 297 - 307.

Robey, D. \& Taggart, W. (1981). Measuring managers' minds: The assessment of style in human information processing. Academy of Management Review, 6, 375 - 383.

Sein, M. K. \& Robey, D. (1991). Learning style and the efficacy of computer training methods, Perceptual and Motor Skills, 72, 243-248.

Sharma, S. (1986). Learners' cognitive styles and psychological types as intervening variables influencing performance in computer science courses. Journal of Educational Technology Systems, 15, 4, 391-399.

Sonnier, I. L. (1990). Hemisphericity: A key to understanding individual differences among teachers and learners. Journal of Instructional Psychology, 18, 1, 17-22.

Sparks, B.I., (1990) The Kolb Learning styles Inventory: predicting academic potential among optometry students. Journal of Optometric Education, 2, 52-55. 
Sperry, R. W. (1964). The Great Cerebral Commissure, Scientific American, Jan, 42-52, Offprint No 174.

Streufert, S. \& Nogami, G. Y. (1989). Cognitive style and complexity: Implications for I/O Psychology; In Cooper,E.L., Robertson,I., (Eds), International Review of Industrial and Organisational Psychology: Chichester, Wiley.

Schweiger, D. M. (1983). Measuring managers' minds: A critical reply to Robey and Taggart. Academy of Management Review, 8, 143 - 151.

Taggart, W., Robey, D. \& Kroeck, K. G. (1985). Managerial Decision Styles and Cerebral Dominance: an empirical study. Journal of Management Studies, 22, 2.

Van Blerkom, M.L. (1988) Field dependence, sex role self-perceptions, and mathematics achievement in college students: a closer examination. Contemporary Educational Psychology, 13, 339-347.

Vernon, P.E. (1972). The distinctiveness of field independence. Journal of Personality, 40, 366-391.

Waber, D. (1989). The biological boundaries of cognitive styles: A neurophysiological analysis. In Globerson, T \& Zelniker, T (Eds.), Human Development, Volume 3. Norwood, Jersey: Ablex Publishing Corporation.

Wardell, D.M., \& Royce, J.R. (1978). Toward a multi-factor theory of styles and their relationships to cognition and effect. Journal of Personality, 46, 474-505.

Watson, J.A., \& Brinkley, V.M. (1992) Logo mastery and spatial problem-solving by young children: effects of logo language training, route strategy training, and learning styles on immediate learning and transfer. Journal of Educational Computing Research, $\mathbf{8}$, $4,521-540$.

Widiger, T. A., Knudson, R. M. \& Rorer, L. G. (1980). Convergent and discriminant validity of measures of cognitive styles and abilities. Journal of Personality and Social Psychology, 39, 116-129. 
Witkin, H. A., Dyk, R. B., Faterson, H. F., Goodenough, D. R. \& Karp, S. A. (1962). Psychological Differentiation: Studies of development, London John Wiley and sons.

Witkin, H. A., Oltman, P. K., Raskin, E., \& Karp,S.A. (1971). A manual for the embedded figures tests, Palo Alto,. Calif.: Consulting psychologists press.

Witkin, H. A., Moore, C. A., Goodenough, D. R., \& Cox, P. W. (1977a). Field dependent and field independent cognitive styles and their educational implications, Review of Educational Research, 47, 1, 1-64.

Witkin, H. A., Moore, C. A., Oltman, P. K., Goodenough, D. R., Friedman, F., Owen, D. R. \& Raskin,E. (1977b). Role of the field dependent and field independent cognitive styles in academic evolution: a longitudinal study. Journal of Educational Pychology, 69, 3, 197-211.

Zeleny, M. (1975). Managers without management science, Interfaces, 5, 35-42.

Zelniker, T. (1989). Cognitive Style and Dimensions of Information Processing. In Globerson,T., Zelniker,T., (Eds.), Cognitive Style and Cognitive Development, Norwood,N.J.: Ablex Publishing Corporation.

Zelniker, T. \& Jeffrey, W. E. (1976). Reflective and Impulsive Children: Strategies of information processing. Monographs of the Society for research in child development. 41, 5. Serial No 168. 
Table I. Gender, Performance and Descriptive Statistics for the Cognitive Style Index

\begin{tabular}{|c|c|c|c|c|c|c|c|c|c|c|c|}
\hline Cognitive Style / Unit of study & $n$ & & Mean & & $S D$ & & Range & $d f$ & & $t$ & \\
\hline Cognitive Style (whole group): & 421 & & 42.72 & & 11.78 & & $5-73$ & 419 & & $2.71 * *$ & \\
\hline Male group & 218 & & 41.23 & & 11.66 & & $5-73$ & & & & \\
\hline Female group & 203 & & 44.32 & & 11.72 & & $9-70$ & & & & \\
\hline Overall Degree (whole group): & 366 & & 10.00 & & 1.66 & & $2.4-13.8$ & 364 & & 1.24 & \\
\hline Male group & 183 & & 9.89 & & 1.73 & & $2.4-13.8$ & & & & \\
\hline Female group & 183 & & 10.11 & & 1.59 & & $4.2-13.6$ & & & & \\
\hline Business Policy and Strategy Unit (whole group): & & 364 & & 9.47 & & 2.18 & & 5.0 & 362 & & 0.63 \\
\hline Male group & 182 & & 9.40 & & 2.12 & & $3.0-15.0$ & & & & \\
\hline Female $\quad$ group & & 182 & & 9.54 & & 2.23 & & 5.0 & & & \\
\hline Marketing Planning Unit (whole group): & 194 & & 9.95 & & 2.02 & & $3.0-15.0$ & 192 & & -1.20 & \\
\hline Male & 103 & & 10.12 & & 2.00 & & $4.0-15.0$ & & & & \\
\hline Female & 91 & & 9.77 & & 2.03 & & $3.0-14.0$ & & & & \\
\hline Research Dissertation Unit (whole group): & 401 & & 10.01 & & 3.00 & & $0.0-16.0$ & 399 & & -0.17 & \\
\hline Male & 207 & & 10.03 & & 2.94 & & $1.0-16.0$ & & & & \\
\hline Female & 194 & & 9.98 & & 3.07 & & $0.0-16.0$ & & & & \\
\hline
\end{tabular}

$* * p<0.01$ (2-tailed) 
Table II. Influence of Cognitive Style on Performance of Analytic and Intuitive Groupings

\begin{tabular}{|c|c|c|c|c|c|c|c|c|c|}
\hline \multirow[t]{2}{*}{ Unit of study } & \multicolumn{3}{|c|}{ Intuitive Individuals } & \multicolumn{5}{|c|}{ Analytic Individuals } & \multirow{2}{*}{$\begin{array}{l}\text { Sig. } \\
\text { (2-tailed })\end{array}$} \\
\hline & $n$ & Mean & $S D$ & $n$ & Mean & $S D$ & $d f$ & $t$ & \\
\hline Overall Degree Grade & 176 & 9.77 & 1.65 & 190 & 10.20 & 1.66 & 364 & $-2.47^{*}$ & .014 \\
\hline Business Policy and Strategy & 174 & 9.33 & 2.17 & 190 & 9.59 & 2.19 & 362 & -1.12 & .262 \\
\hline Marketing Planning & 88 & 9.56 & 2.07 & 106 & 10.28 & 1.92 & 192 & $-2.52 * *$ & .013 \\
\hline Research Dissertation & 192 & 9.70 & 2.89 & 209 & 10.30 & 3.07 & 399 & $+2.05^{*}$ & .041 \\
\hline
\end{tabular}

$* p<0.05$ (2-tailed), $* * p<0.01$ (1-tailed) 


\begin{tabular}{|c|c|c|c|c|c|c|c|c|c|c|c|}
\hline \multirow[t]{2}{*}{$\underline{\text { Unit of study }}$} & \multicolumn{3}{|c|}{ Intuitive Types } & \multicolumn{3}{|c|}{ Integrated Types } & \multicolumn{5}{|c|}{ Analytic Types } \\
\hline & $n$ & Mean & $S D$ & $n$ & Mean & $S D$ & $n$ & Mean & $S D$ & $d f$ & $\boldsymbol{F}$ \\
\hline Overall Degree Grade & 113 & $9.74_{3}$ & 1.82 & 122 & 10.03 & 1.41 & 131 & $10.20_{1}$ & 1.73 & 2,363 & $2.32 *$ \\
\hline Business Policy and Strategy & 112 & $9.33_{3}$ & 2.35 & 121 & $9.15_{3}$ & 2.30 & 131 & $9.88_{1,2}$ & 1.83 & 2,361 & $3.91 * *$ \\
\hline Marketing Planning & 57 & $9.40_{3}$ & 2.23 & 64 & 10.06 & 1.73 & 73 & $10.29_{1}$ & 2.02 & 2,191 & $3.29 * *$ \\
\hline Research Dissertation & 123 & 9.78 & 2.96 & 133 & 10.06 & 2.93 & 145 & 10.15 & 3.10 & 2,398 & 0.54 \\
\hline
\end{tabular}

$* p<0.1, * * p<0.05 \quad$ Subscript to a mean refers to a group whose mean is significantly different (Duncan multiple range test). 
Table IV. Methods and Criteria of Assessment

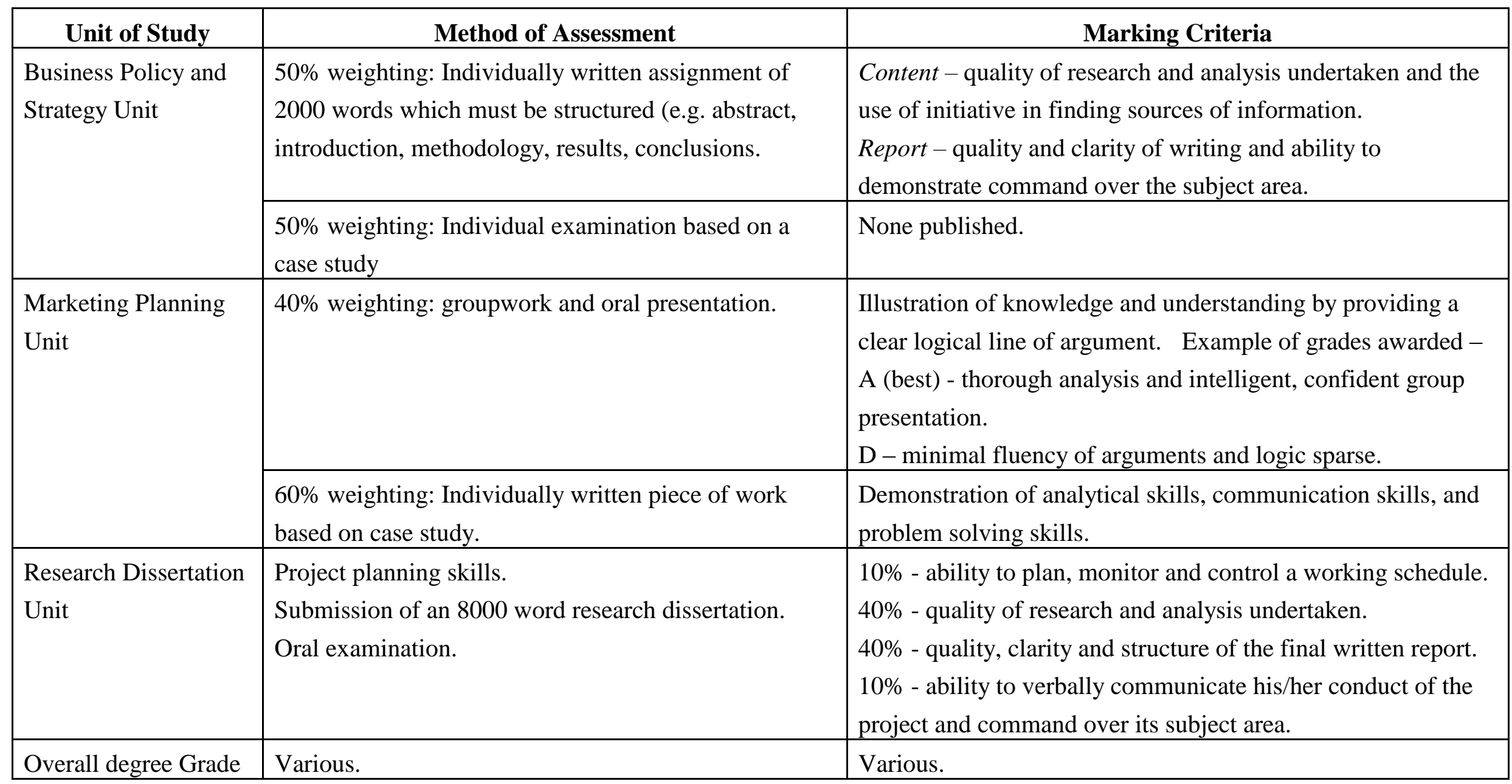

